\title{
An evaluation of alternative coating material laminated marble in Turkey
}

\author{
Y. Arat \\ Department of Architecture, Necmettin Erbakan University, Meram, Konya, TURKEY \\ E-mail: yavuzarat@gmail.com
}

Received: December 21, 2015; Revised received: April 2, 2016; Accepted: June 7, 2016

\begin{abstract}
The natural stones stand at a significant point of human life from the existence of human-life to present time with their durable and persistent features. They have been used as an important construction material until the recent past. Although the production of marble material is widespread in Turkey, the conversion to the final case marble material is not observed prevalently. The aim of this study, the evaluation of the laminated marble material in terms of being used in architecture and the types of the advantages presented by the material are all listed at the end of the research. The results obtained from the architectural coating application carried out to examine the preferable reasons between marble and laminated marble are thought to have advantages in terms of flawless connection details, easy application, transportation and storage processes in comparison to the marble material for the case of coating surfaces with similar quality. The laminated marble material is more durable by the effect of 9 $\mathrm{mm}$ porcelain ceramic at the bottom than the traditional marble plate of $3 \mathrm{~mm}$ thickness and is nearly $50 \%$ lighter than the marble material having the same thickness and sizes with the laminated marble material that is clear that nearly $50 \%$ decrease in transportation costs will be expected. When viewed from this aspect, the new construction materials obtained by reconsidering and re-developing the natural materials in accompany with the innovativetechnological methods will contribute easy and eco-friendly to the architectural design-application projects especially in terms of easy application and utilization.
\end{abstract}

Keywords: Architecture, Coating application, Decoration, Laminated marble, Marble, Natural stone

\section{INTRODUCTION}

The durability and persistency characteristics of natural stone material have great importance in the context of utilization period-cost-efficiency depending on the developments in material technology. Additionally, the use of natural stone materials is the most common subject discussed in sustainable architecture and ecologic design concepts due to their ability of presenting distinctive alternatives for environmentally-conscious architectural designs. At this point, since Turkey has $40 \%$ of marble reserve on the world, the development of marble material within the context of natural and local construction material in company with technological-innovative comments will present a prosperous alternative in terms of selecting-utilizing construction materials for sustainable and ecological architecture design-application projects (Tosun and Tatar, 2007).

The method of the research is based on the evaluation of the advantages and disadvantages in terms of architectural application projects which will be provided as a result of the detection-observation studies and oral interviews performed at Casvino laminated marble production facility existing at the Xiamen city of People's Republic of China. Within this scope, the marble and laminated marble materials are evaluated in terms of ease of use-application potential in architectural application projects.
The objective of this research is to investigate the easy utilization-opportunities provided by the laminated marble material in architectural design-application projects which was newly manufactured as a result of the combination of marble material together with the ceramic/porcelain material in accompany with innovative-technological methods. This research involves the supply-chain of the laminated marble from the manufacturing process to the storage-transportationmarketing stages and the evaluations related to the utilization-application processes of laminated marble material.

Natural marble: The polishable rocks having various appearances, textures and colors are commercially called as "marble". Most of the rocks having these features are called either directly "marble" or "crystalline limestone". The principal mineral of most of the marbles is calcite (Özgül, 2010). It is possible to classify marbles according to their formations such as genuine marbles, crystallized limestone, travertines and onyxes, magmatic marbles and tuffs (Tavşan, 2012).

There are two descriptions of marble in terms of science of geology aspect and commercial aspect. The stones formed by either the conversion of limestones subjected to metamorphism under high temperature and pressure or the new structure of limestones $\left(\mathrm{CaCO}_{3}\right)$ and dolomic-limestones $\left(\mathrm{CaMg}\left(\mathrm{CO}_{3}\right)_{2}\right)$ gained as a result of re-crystallization occurred after 
metamorphism under heat and pressure is called as "marble" (Orangan et al., 2006).

The commercial definition; is given as "all types of rocks that can be cut, polished and formed as a block appropriate to commercial standards or whose surface can be treated and material properties are convenient for coating stone norms are called as "marble". From this point of view, whatever the type of rock and its contents, it is enough for us to accept a stone as "marble" due to its cuttable and polishable characteristics and the opportunity of obtaining large size block. The magmatic rocks such as granite, syenite, gabbro, basalt, andesite and serpentinite, the metamorphic rocks such as marble and the sedimentary rocks such as limestone, travertine, dolomite, sandstone and conglomerate are industrially and commercially included in the definition of "marble". Furthermore, the plates obtained from minerals such as calcite and aragonite are called as "onyx marble" in the market. In the commercial definition, the "marble" word does not define the rock type (Caran, 2014).

Turkey with its dynamic population and significant underground and ground natural sources increases its level of development day by day. Moreover, the marble sector growing parallel to the fast-growing mining sector in Turkey develops with a rapidly increasing acceleration and exists at the top of the mining sector for years. The marble sector has been born as a result of natural stones having been used as construction materials for many years. Today, marble industry is one of the most important sector on the world especially in Italy, Spain, Portugal, Greece, Brazil, Republic of South Africa, China and in many countries where high technologies are used (Altınçiçek, 2001; Keleş et al., 2014). On the other hand, the first five countries exporting natural stone on the world are Turkey, Italy, Spain, Portugal and Egypt, and the countries taking the highest share for the mined product can be listed as Turkey, Italy and Spain.

Since the location of Turkey is at the AlpineHimalayan Orogeny Zone, there exist many types of natural stones in Turkey. Additionally, nearly the $40 \%$ of the marble reserve of the world, i.e. 5.2 billion $\mathrm{m}^{3}$ (13.9 billion tons) is estimated to be existing in Turkey (Özçelik et al., 2014).

Laminated marble: The laminated marble is a new kind of construction material formed by the combination of the natural stone at low sections with porcelain material which presents various advantages of smooth surface, regular dimension and less cross-section without losing the characteristics of the natural stone. There is a special chemical combining the porcelain material with marble material which prevents the differentiation by reaching the similar expansion coefficient. Many advantages of laminated marble material were determined and the widespread use of marble again as a construction material was provided by the aid of the formation of marble material using new technology and easy surface treating techniques with fabrication.

The factories producing laminated marble material take place in abroad that the laminated marble manufactured in Canada, Italy, Malaysia and People's Republic of China is scattered all over the world. In our country, since we have no research or study about laminated marble technology, we import laminated marble from People's Republic of China under different brand names to take part in our construction material market.

The production stages of laminated marble material vary with respect to the demanded material that the production stages of the surfaces with single color or single type of marble and the surfaces formed by the combination of marbles of several textures and/or colors differ from each other partially. After cutting the marble blocks plate by plate, the marble plates pass through the quality-control process and are separated for the porcelain ceramics to be stuck on the marble plates (Plates 1-4). The marble plates cut with $16 \mathrm{~mm}$ or $20 \mathrm{~mm}$ thickness are then sized to desired dimensions. Then, $9 \mathrm{~mm}$ thick porcelain ceramic is stuck on the marble material of $300 \times 600 \mathrm{~mm}, 600 \times 600 \mathrm{~mm}$, $800 \times 800 \mathrm{~mm}$ and $600 \times 1200 \mathrm{~mm}$ dimensions on two sides, and then the material is pressed and left to get dry. Later, the marble material whose two sides are ceramic now is cut directly from the center to obtain two separate pieces (Plate 5). Then sticking to its one surface, the same process is repeated. In this way, four pieces of $14 \mathrm{~mm}$ thickness formed by $9 \mathrm{~mm}$ porcelain ceramic and $5 \mathrm{~mm}$ marble are obtained. After calibrating these pieces, full-sized material is obtained (Plate 6). If the marble plate is $16 \mathrm{~mm}$, this size turns into the pieces of $4 \mathrm{~mm}$. The most interesting aspect of this material is the water jet embroideries. The models cut in the factory with water jet are placed one by one by the relevant workers, and the ornamented materials are obtained. Since the manufactured material is obtained using piecewise material, the product sizes are measured at every turn and the full-size of the material is obtained. Furthermore, the material precisely produced one by one and stored in the factory can be studied as a whole to obtain larger motifs of $1600 \times 1600$ or $1200 \times$ $1200 \mathrm{~mm}$ sizes.

Comparison of natural marble and laminated marble: Here, the natural marble and laminated marble are comparatively evaluated in the context of application process by considering the utilization opportunity and easiness.

The marble material is produced with $20-30 \mathrm{~mm}$ thicknesses; however they are used as the plates of 4-5 mm thicknesses for the application processes, then it is possible to talk about unfavorable effects in terms of environmental awareness based on overproducing and consuming materials using natural sources. On the other hand, the laminated marble provides economy in terms of the surface obtained during the production 


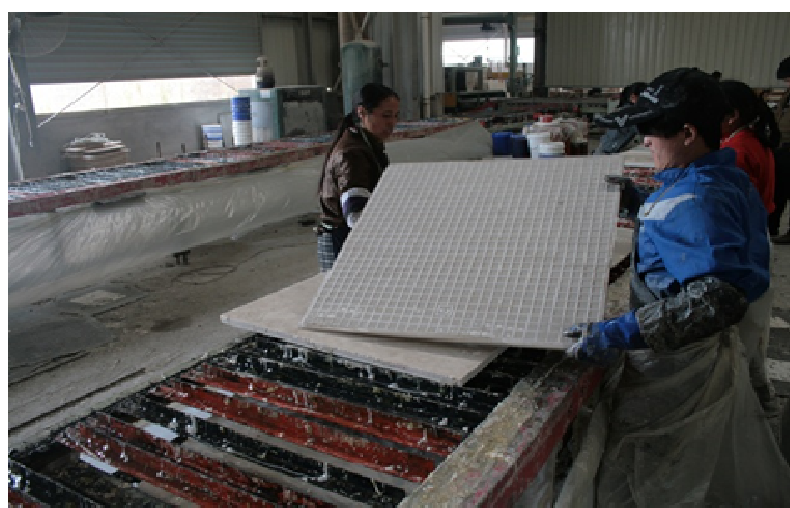

Plate 1. Sticking process of marble plate with the porcelain ceramic

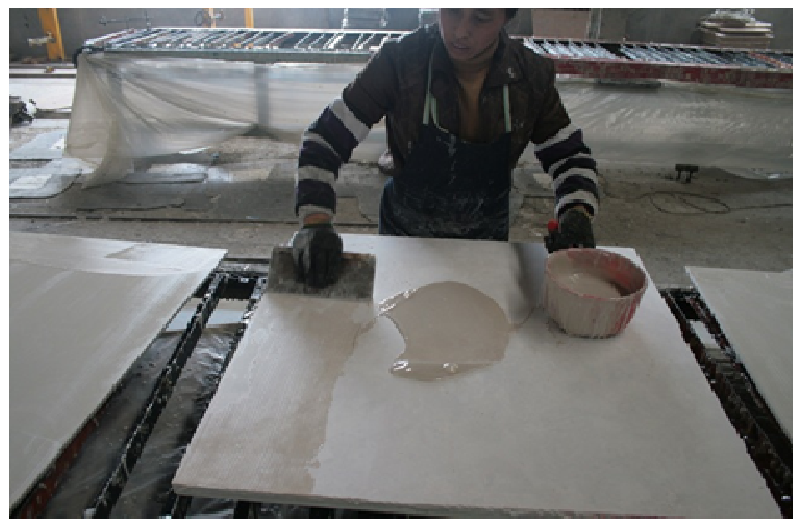

Plate 2. Chemical applied on the marble plate

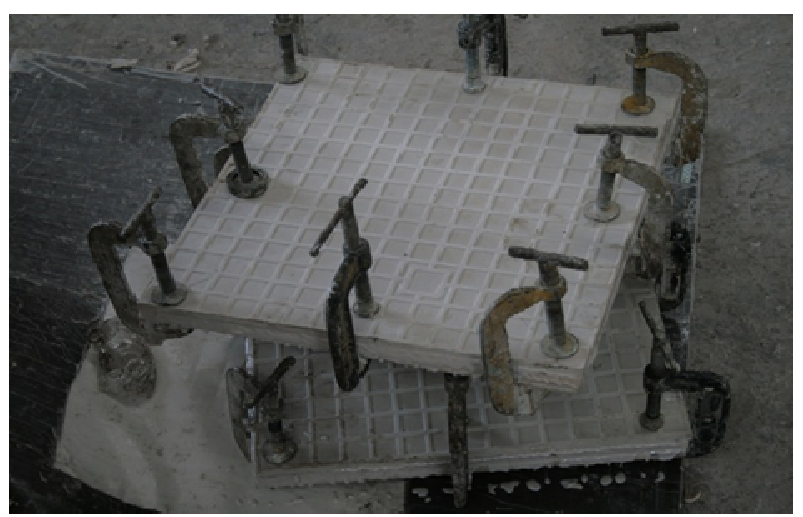

Plate 3. Sticking process of the laminated marble plates

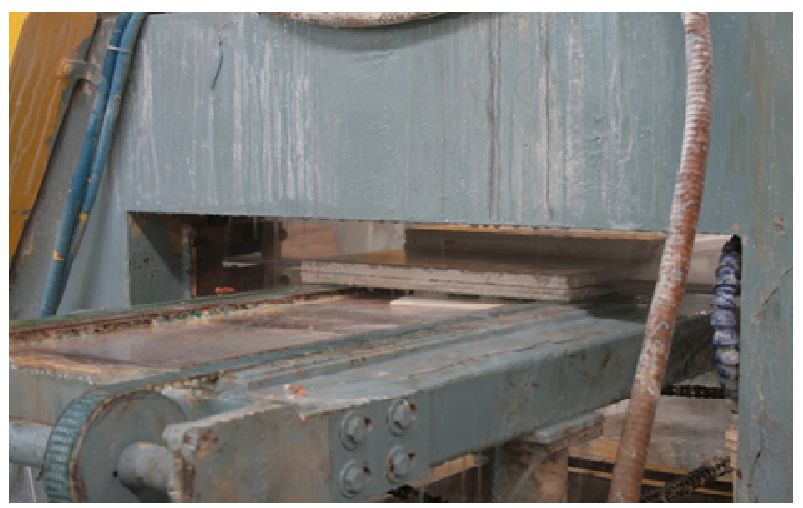

Plate 4. Pressing process of the laminated marble plates

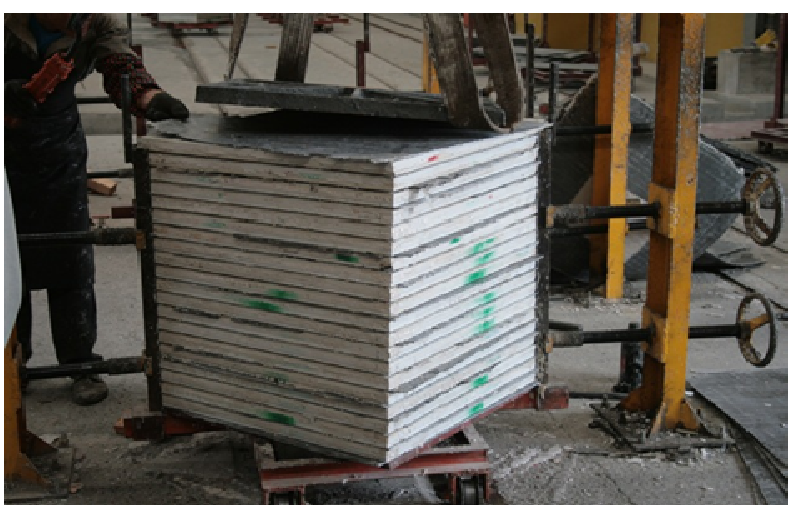

Plate 5. Cutting process of the laminated marble plates

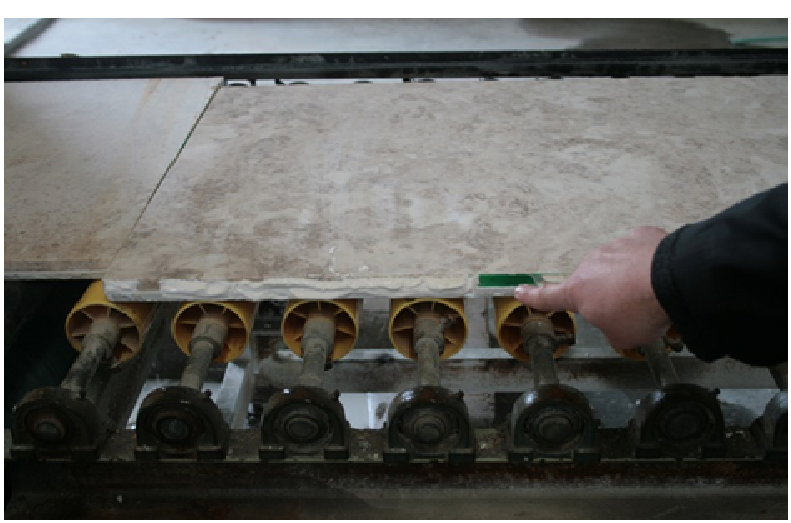

Plate 6. Cleaning process of the cut laminated marble plates

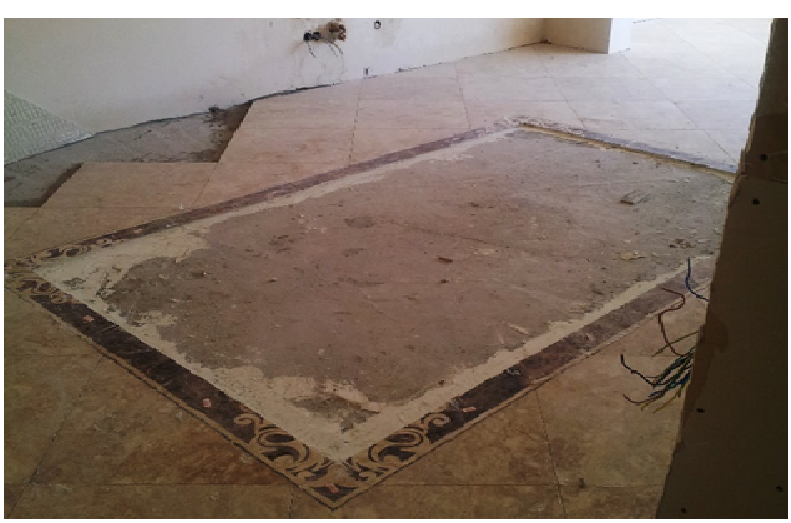

Plate 7. Application of the laminated marble plates

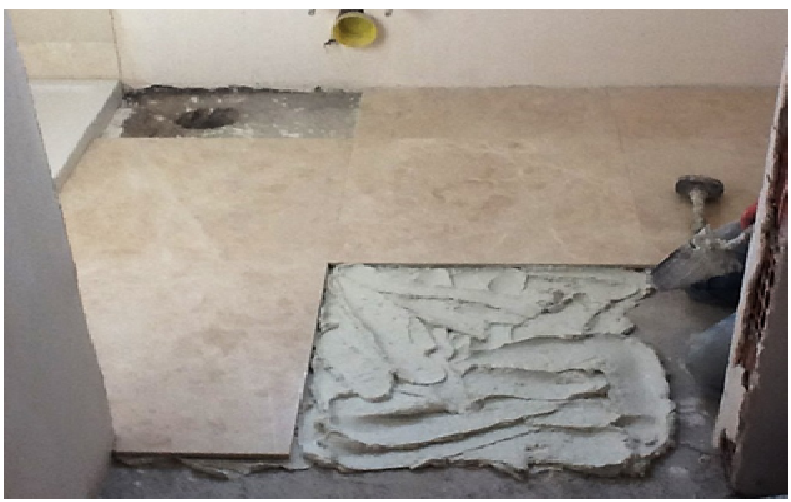

Plate 8. Application of the marble plates 


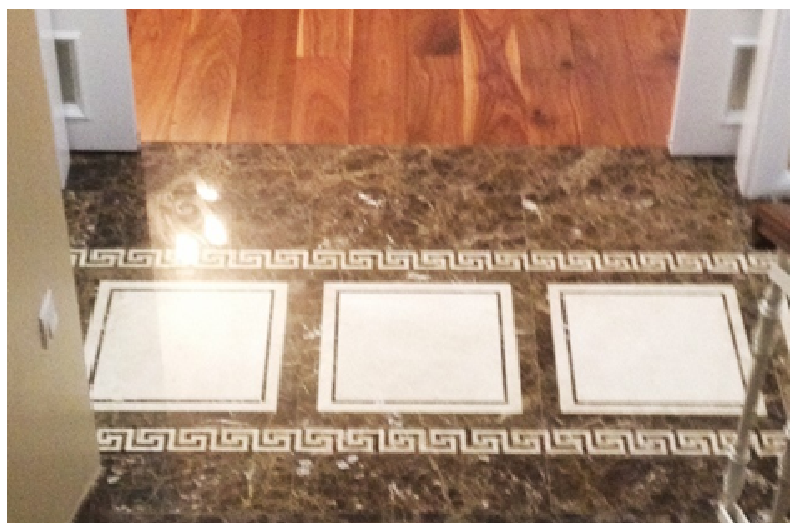

Plate 9. Wooden floor transition with laminated marble plate

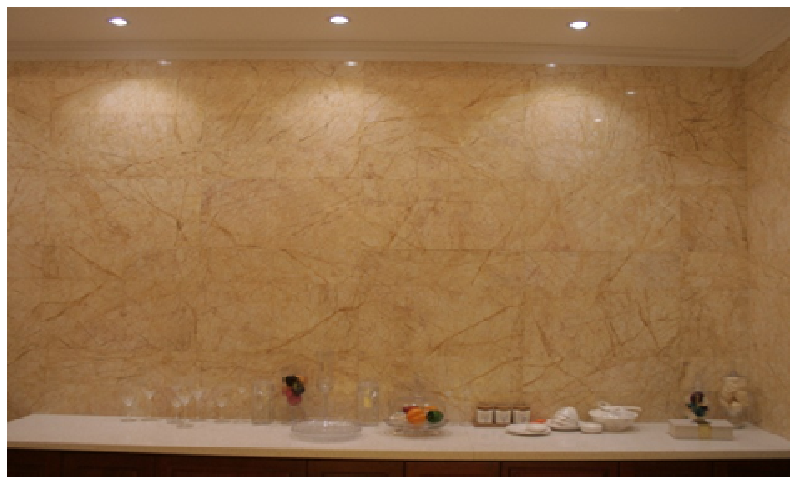

Plate 10. Jointless wall covering with laminated marble plate

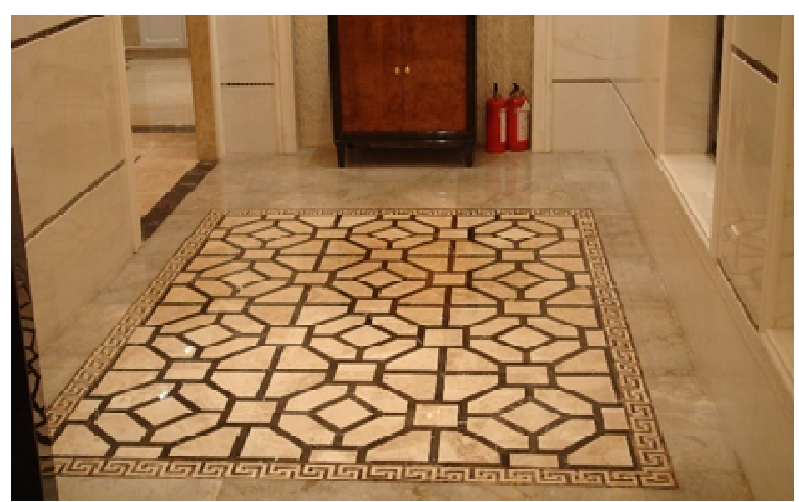

Plate 11. The jointless floor application with laminated marble plates

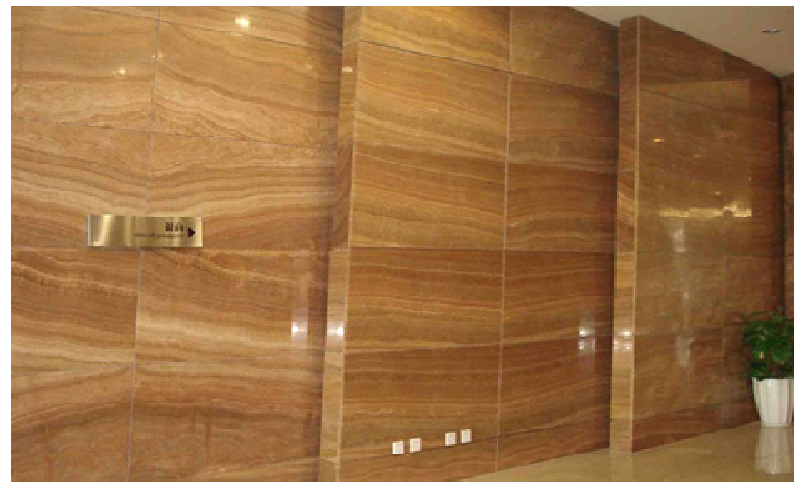

Plate 12. The jointed wall covering with marble plate

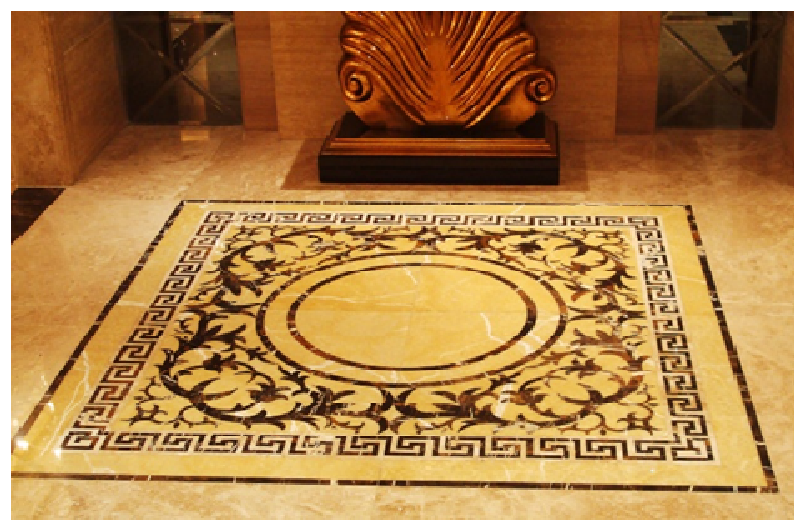

Plate 13. Ready-made floor produced by laminated marble

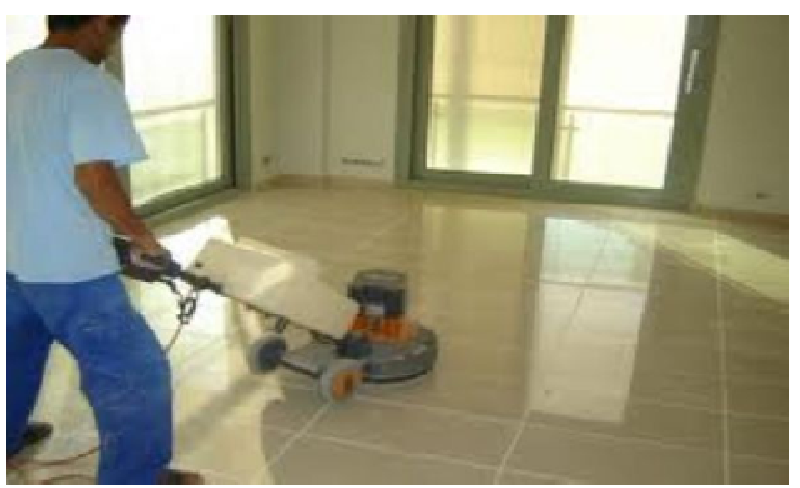

Plate 14. Cleaning and polishing process of the marble floor (Source: Faroz Group, 2015)

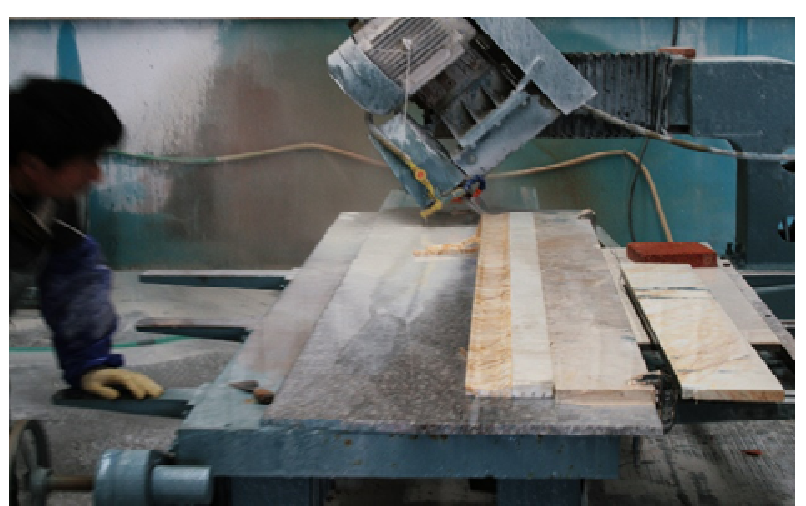

Plate 15. Preparation of the moldings produced with laminated marble at the factory

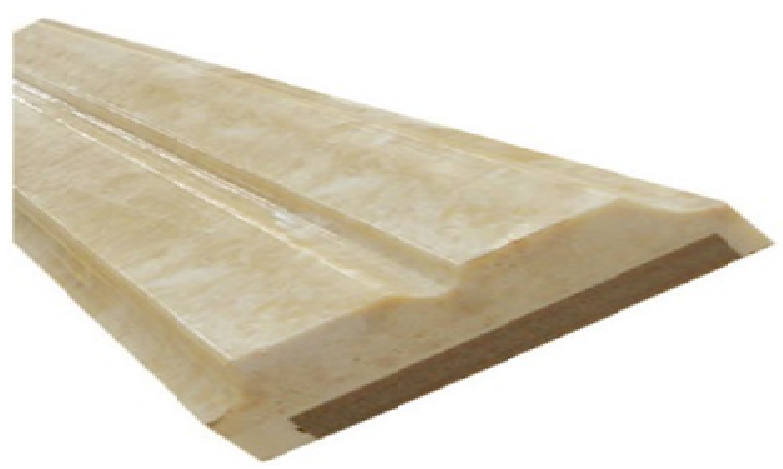

Plate 16. Moldings produced with laminated marble 


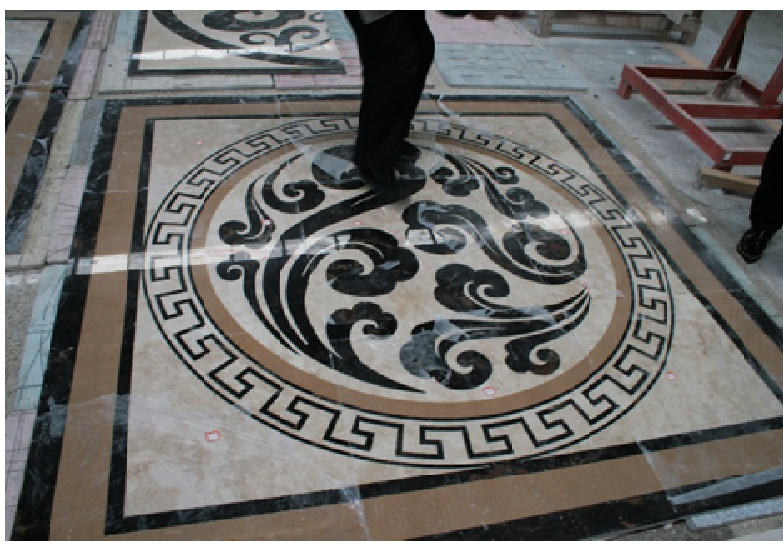

Plate 17. Combination of the ready-made floor at the factory produced by laminated marble material

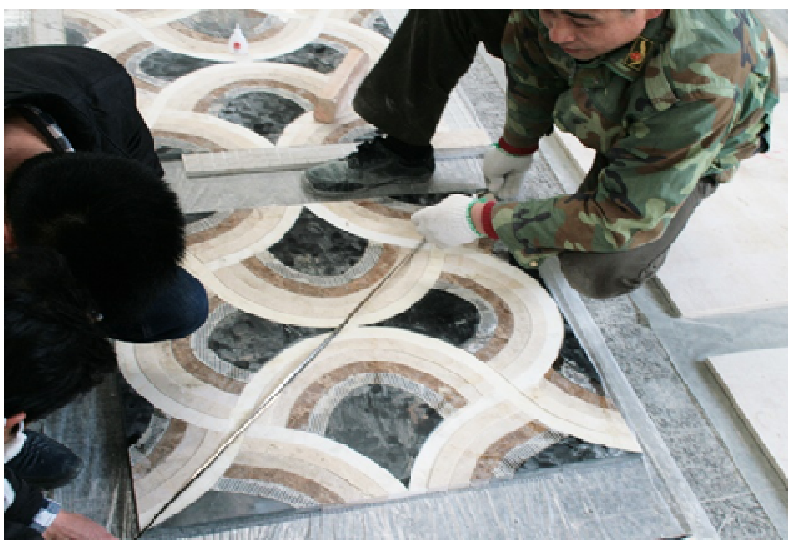

Plate 18. Calibration of the ready-made floor at the factory produced by laminated marble

Table 1. Laminated marble - Natural marble compression. (Source: Laminated Marble (2015), Access date: $3^{\text {rd }}$ April 2015)

\begin{tabular}{lll}
\hline Description & Laminated Marble & Natural Marble \\
\hline Thickness & $12-14 \mathrm{~mm}$ & $18-20($ up to 30$) \mathrm{mm}$ \\
Weight & $32 \mathrm{~kg} / \mathrm{m}^{2}$ & $55 \mathrm{~kg} / \mathrm{m}^{2}$ \\
Tensile Strength & $200 \mathrm{~kg} / \mathrm{cm}^{2}$ & $120 \mathrm{~kg} / \mathrm{cm}^{2}$ \\
Bending Strength & $25.9 \mathrm{MPa}$ & $12.1 \mathrm{MPa}$ \\
Compressive Strength & $<100 \mathrm{MPa}$ & $<100 \mathrm{MPa}$ \\
Stuffing Quality & $700 \mathrm{~m}^{2} / \mathrm{TEU}$ & $350 \mathrm{~m}^{2} / \mathrm{TEU}$ \\
Cost & $50-60 \%$ & $100 \%$ \\
\hline
\end{tabular}

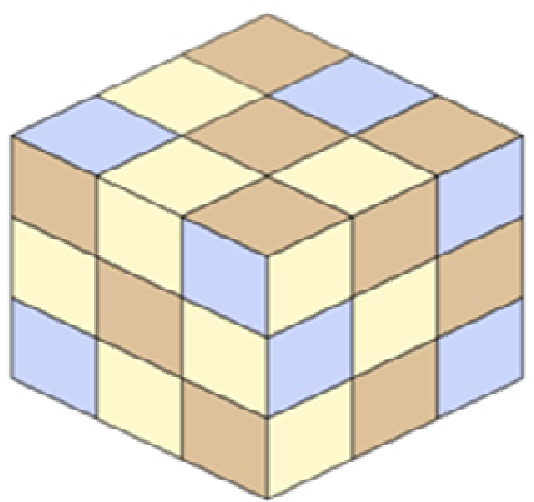

Traditional Marble Plate

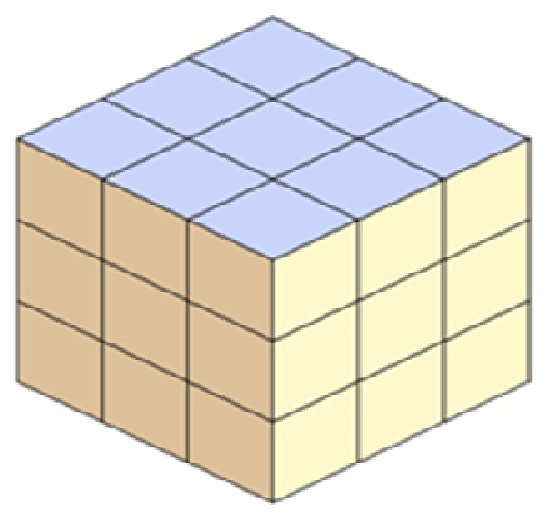

Laminated Marble Plate

Fig. 1. Difference in Color - Tone of marble plates. (Source: Laminated marble (2015), Access date: $3^{\text {rd }}$ April 2015)

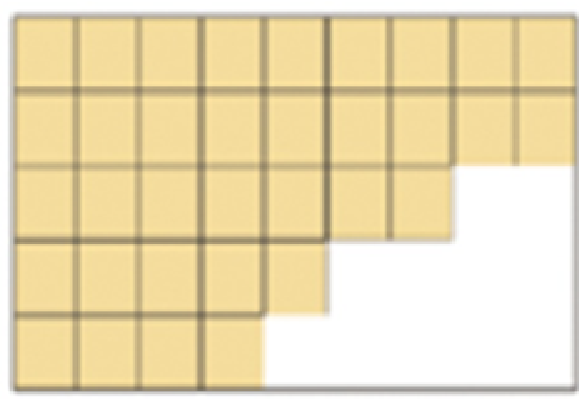

Traditional Marble Plate Application
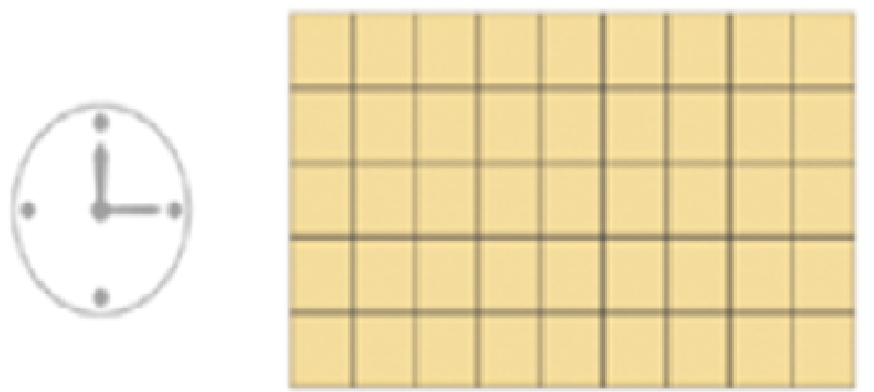

Laminated Marble Plate Application

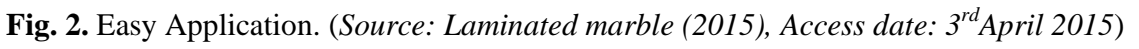




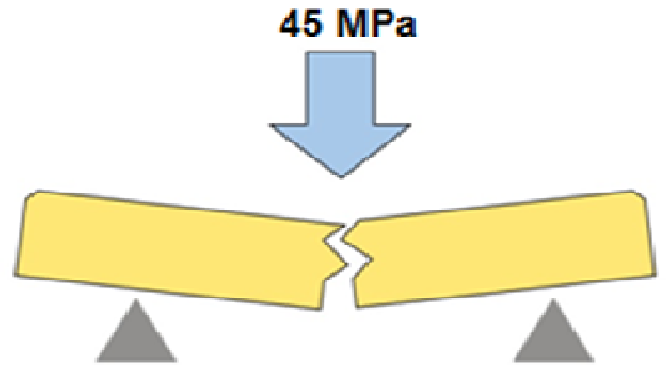

Traditional Marble Plate

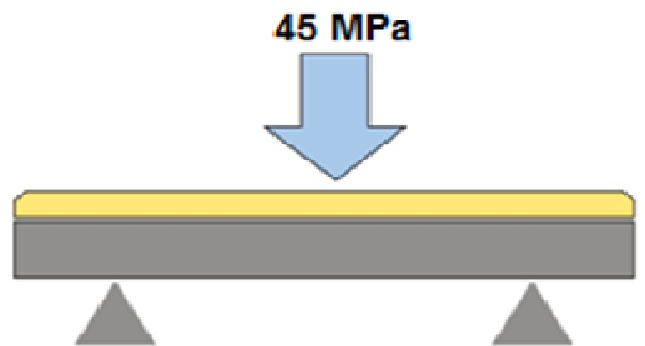

Laminated Marble Plate

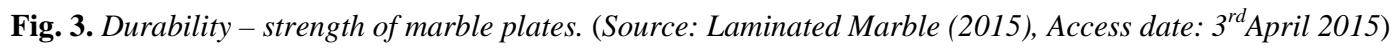
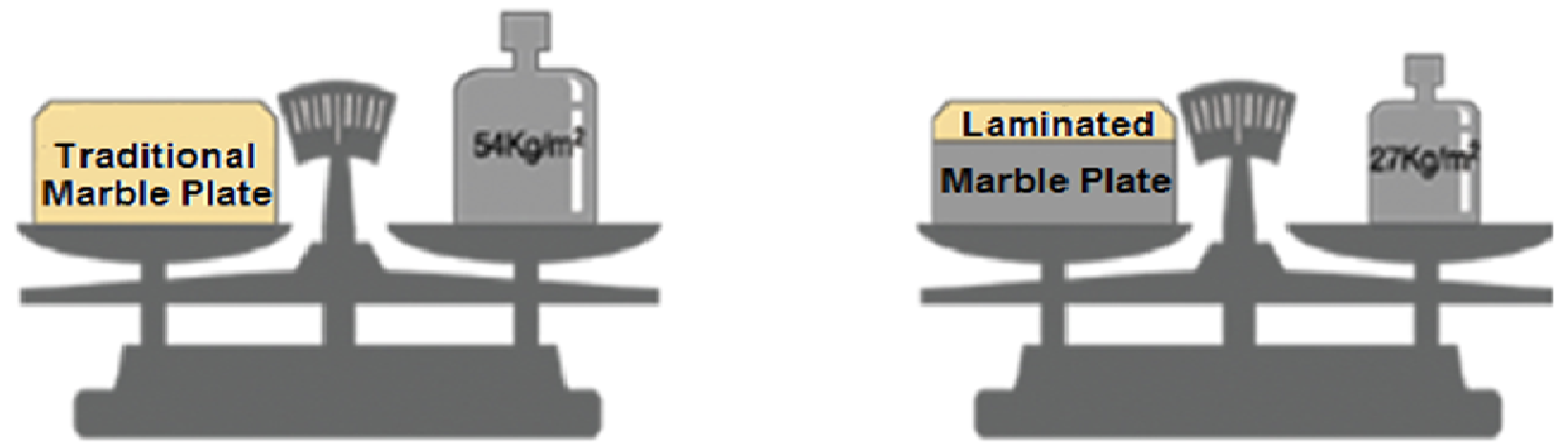

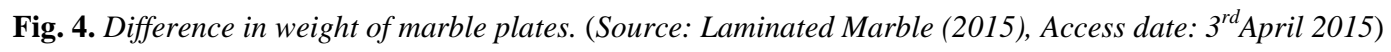
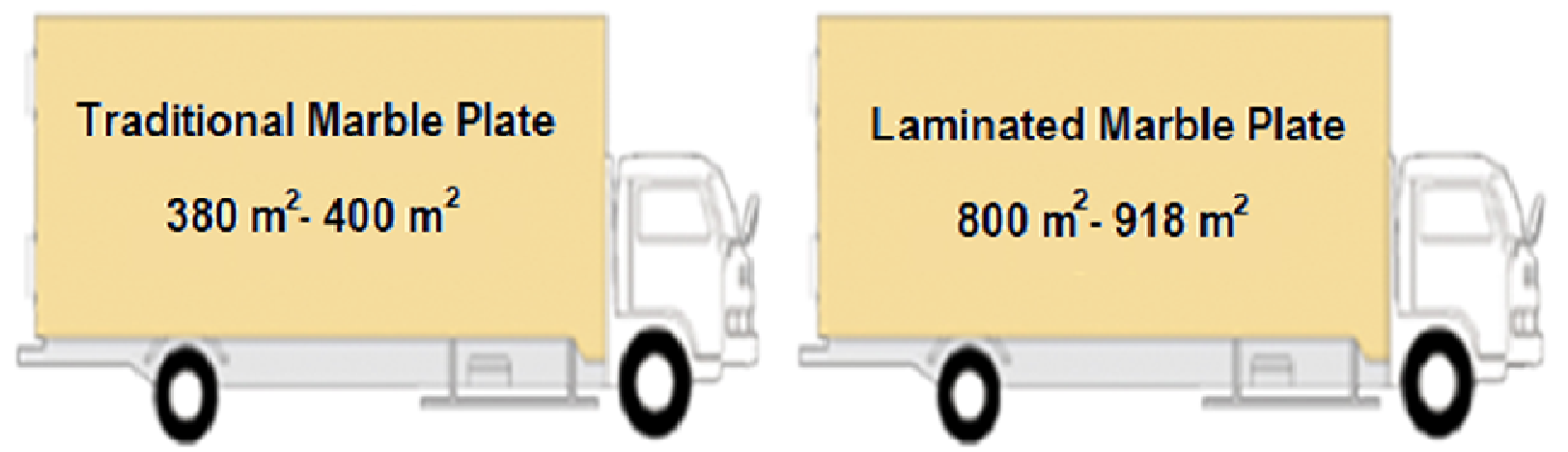

Fig. 5. Difference in transportation carrying capacity of marble plates. (Source: Laminated Marble (2015), Access date: $3^{\text {rd }}$ April 2015)

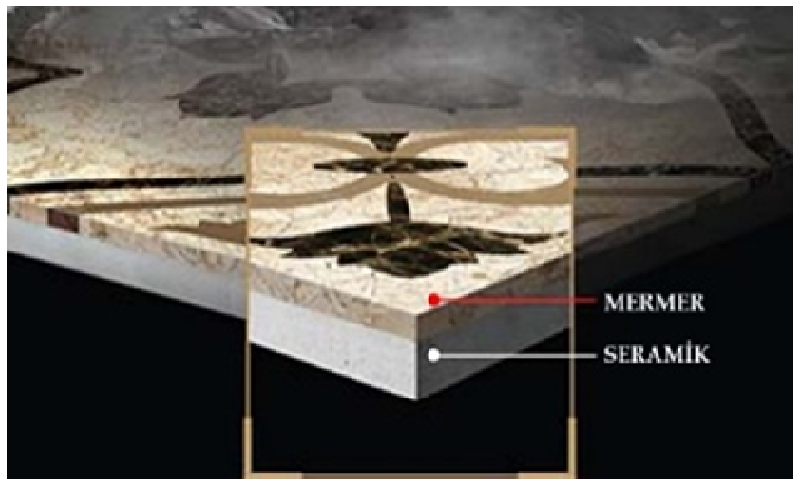

Laminated marble plate cross-section

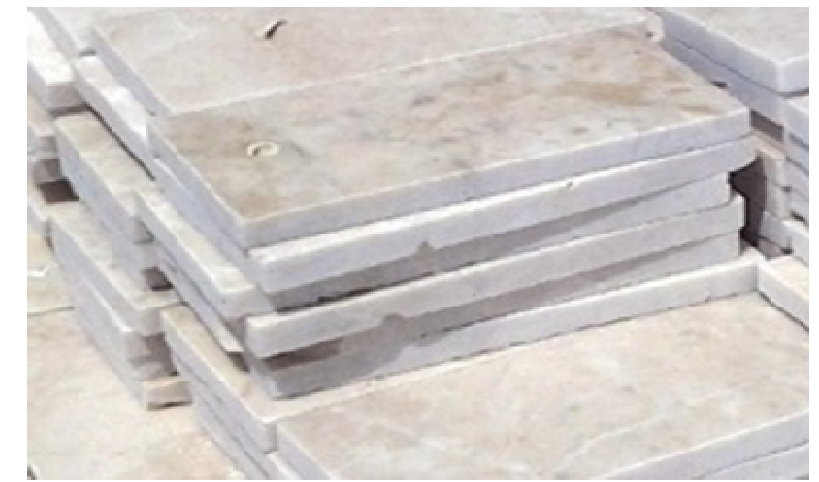

Marble plate cross-section

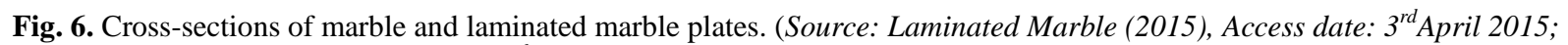
Marmocer Turkey (2015), Access date: $5^{\text {th }}$ April 2015) 


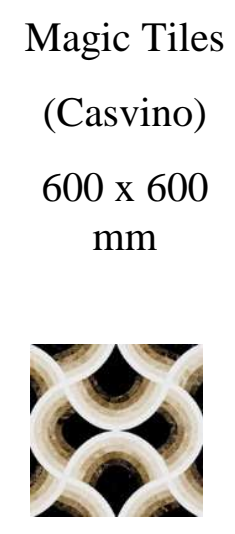

Magic Tiles

(Marmocer)

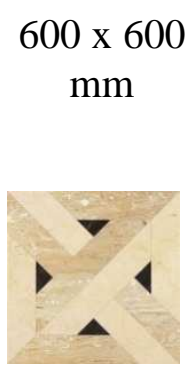

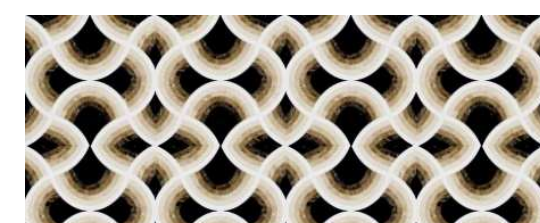
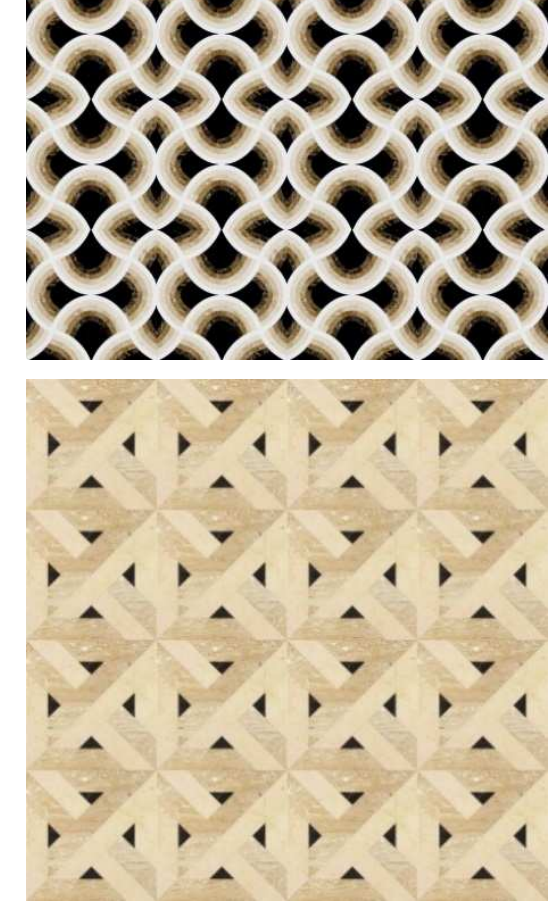

Magic Tiles

(Marmocer)

$600 \times 600$

$\mathrm{mm}$

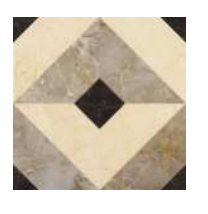

Magic Tiles

(Casvino)

$600 \times 600$ $\mathrm{mm}$

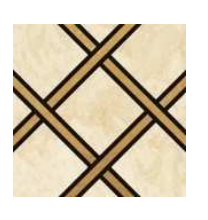

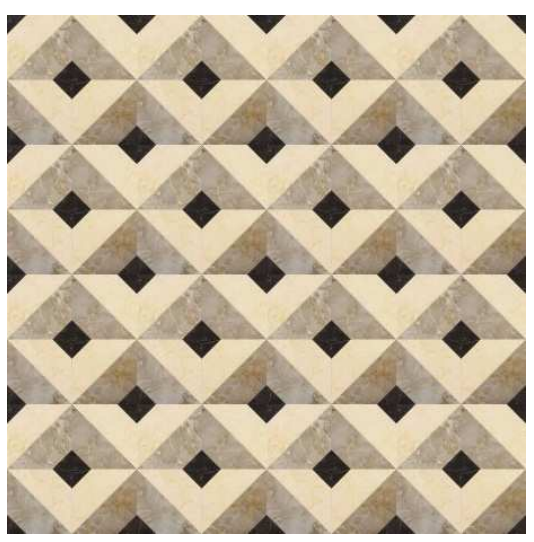

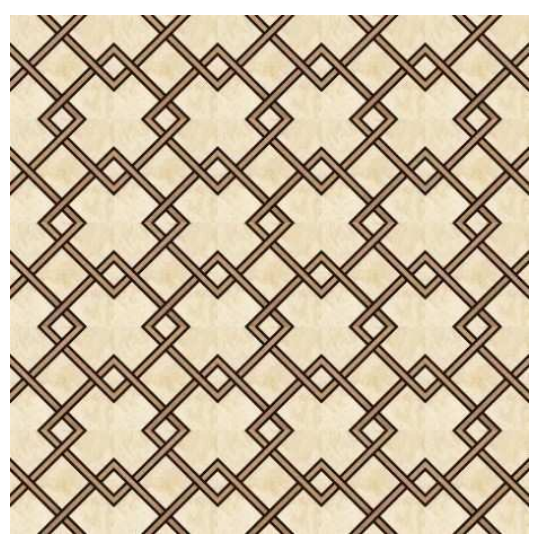

Fig. 7 . Floor types constructed with laminated marble material. (Source: Casvino MarbleCer (2015), Access date: $5^{\text {th }}$ April 2015; Marmocer (2015), Access date: $5^{\text {th }}$ April 2015)

stage and the package sizes/dimension. Moreover, the laminated marble production provides five times more surface than the surface obtained from a natural marble block. In addition, it is understood that the laminated marble material is more practical in comparison to natural marble material in terms of the opportunities of reparability where it may be necessary due to the damages while cutting either during the production stage or the application-utilization stages. This is an important advantage affecting the material use and labor costs directly. Therefore, it can be easily told that the laminated marble has significant advantages in terms of economical application costs and selecting and using natural material in architectural design-application projects.

In the context of tone and texture differences, marble material is said to present restrictive alternatives for tone transitions during the utilization-application processes. On the other hand, since laminated marble is produced as a result of a standard production process based on fabrication technique, it has rich alternatives in terms of providing harmony-unity for tone transitions and tone-texture differences (Fig. 1). In connection to these features of laminated marble, it has considerable advantages in terms of the aesthetical-visual harmony and presentation of the material in the architectural design-application projects. Since the standard calibration is not possible during the production process in terms of sizing the marble material, there are met significant problems during the packaging and application processes. On the other side, the ready-made material property of the laminated marble material produced with 4-5 mm thickness by joining marble and porcelain/ceramic materials together during the standard production period based on fabrication processes provides saving on time especially during the utilization and application periods and decreases the labor cost due to easy applicability (Fig. 2 , Plates 17, 18). Moreover, being the material prepared with water jet during its continuous production stage, the laminated marble material causes to have easy application at the site only by using ceramic adhesive and excellent connection details. The laminated marble material is stored at the factory by applying transparent adhesive film on the surfaces of the material which is peeled off after the completion of the application, and the floor/wall becomes ready for use.

It is possible to say that the laminated marble material is more durable in comparison to marble material within the context of production technology that the marble material is produced up to $20-30 \mathrm{~mm}$ crosssection thicknesses while the laminated marble material has 4-5 mm thicknesses. Hence, the experimental studies prove that, in terms of compression, the laminated marble material is more durable by the effect of $9 \mathrm{~mm}$ porcelain ceramic at the bottom than the tradi- 
tional marble plate of $3 \mathrm{~mm}$ thickness (Fig. 3).

On the other hand, if marble and laminated marble materials are compared with each other in terms of their weights; the laminated marble material of $2 \mathrm{~cm}$ thickness is nearly $50 \%$ lighter than the marble material having the same thickness and sizes with the laminated marble material (Fig. 4). This situation presents significant advantages related to easy utilization and application processes and especially in terms of transportation-storage costs.

As a matter of fact, if a comparison was carried out between marble and laminated marble in terms of transportation cost and capacity; while maximum 380 $\mathrm{m}^{2}$ of natural marble material can be carried by a container, this capacity rises up to nearly $918 \mathrm{~m}^{2}$ amount of laminated marble material for the same size of container. Therefore, depending on the increase in carrying capacity, it is clear that nearly $50 \%$ decrease in transportation costs will be expected (Fig. 5). Consequently, these results can be seen as a significant advantage of laminated marble in terms of usability and widespread demanding.

Another subject within the context of demand-supply equilibrium is; whether the possible demand in the market will be fastly met on-time or not, which should be considered as an important criterion affecting the cost and marketing opportunities in terms of the completion of the architectural projects especially during the application period. Therefore, it is determined that the demands for the laminated marble material by considering the standard production with fabrication can be met utmost two months period of time including the production-transportation processes. From this aspect, it is understood that the laminated marble material is produced in a shorter period of time.

Coating applications of laminated marble: The characteristic of the laminated marble material that is suggested to bring innovations to marble applications is well-explained in details by this research. All in all, the use of laminated marble reveals some advantages considering the instinct of a qualified-use of natural materials whose formation takes a long period of time and the exhaustion risk of natural sources. Thus, the questioning of the quality of the advantages met during the application is explained by the photographs taken during the application of laminated marble material within the scope of this research. In this context, the laminated marble incomparably comes into the forefront at the application-sites due to elaborate material production (Fig. 6, Table 1). Especially the varying crosssection thicknesses of the materials facilitate the level adjustment for the floor applications.

At the beginning of the application, the floor preparation process for two materials is demanded to have the same quality. In this context, while the marble application process on the wall or floor is performed only by using marble adhesives, the application of laminated marble material can be made using both marble and ceramic adhesives (Plates 7, 8 and 12). The ceramic bottom of the laminated marble causes the application of laminated marble to be performed with the same workmanship as carried out for the ceramic applications. At this point, full size material characteristic of laminated marble provides the chance of making jointless i.e. integrated floor application (Plates 9, 10).

For a surface required to be covered with marble, the floor covering is completed by filling joint-sealant into the joint spaces occurred due to the applied material's calibration differences. However, a continuous smooth surface can be obtained as a result of the jointless applicability feature of laminated marble material that this ability and easiness of using laminated marble material became the most conspicuous property of the material during the studies of this research (Plate 11). While the traditional marble plates are polished in-situ after the application, the laminated marble floor becomes ready after the application only by removing the transparent films on the surfaces applied at the factory after cleaning and polishing the material at the factory (Plates 13, 14).When the columns, moldings and finishings are produced full of marble material, they are strengthened with aluminum fasteners and again used as coating material by bringing the ceramic bottom plate (Plates 15, 16). At this point, instead of the filled materials increasing the weight of the structure, the laminated marbles seem to be more advantageous to be used as the coating material. Moreover, the formation of various textures and shapes by joining the marbles of various colors and textures together in the factory is one of the biggest innovations gained by the laminated marble material. Beside this, the floors obtained by repeating the same or different laminated marble plates and the largest motifs formed by using small pieces increase the quality of the laminated marble material considerably. The detail and floor shapes extremely difficult to be built using traditional marble plates are easily formed and applied using laminated marble material (Fig. 7, Plate13).

As a result, marble, one of the most significant natural sources on the world, has been used by people for centuries. Especially due to its durable structure and beautiful natural appearance, the use of marble increased in many sectors particularly in the construction sector. Today, the increasing use of natural stones also increased the demand for marble, and therefore marblemining has reached to a conspicuous position in the mining sector. On the other hand, since marble is a nonrenewable source, the continuously increasing demand for this source caused marble to become more valuable in our country which has limited reserves. Hence, the fast-consumption of marble sources puts forward the obligation of using nonrenewable natural material more effective in a qualified manner.

In other words, the natural stones including marbles are re-preferred after being considered using new technological methods, and the production increased accordingly. This situation played a great role for the 
development of the laminated marble material and increased the utilization areas of the marble material. It is clearly determined that the laminated marble material has some advantages in comparison to the traditional marble material according to the criteria considered within the scope of this research. These advantages and disadvantages would help to decide, whether it would be needed to use laminated marble instead of marble.

There is enormous amount of waste generated during the cutting process of the marble tiles. When marbles are caught up and put on the floor, then there is a lot of wastage, which can be called collateral damage, but nevertheless it makes you lose money. Hence, it would be a better idea to use to any other sort of coating material that can actually have substituted laminated marble, as well as cost less.

Inserting marbles in floors is a time consuming process, and it would require only skilled technicians, that requires a lot of money. Contrary to this, the readymade material property of the laminated marble produced with 4-5 mm thickness by joining marble and porcelain/ceramic materials together during the standard production period based on fabrication processes provides saving on time especially during the utilization and application periods and decreases the labor cost due to easy applicability.

Marble floors are known to be extremely heavy, due to the marbles that have been inserted onto it. Instead of marble, you can choose laminated marble is much more lighter than the same marble material. If marble and laminated marble materials are compared with each other in terms of their weights; the laminated marble material of $2 \mathrm{~cm}$ thickness is nearly $50 \%$ lighter than the marble material having the same thickness and dimensions.

In addition to this, the laminated marbles provided marble to take its place in current use once again for thinner sections together with the porcelain material. By this research, the advantages and disadvantages of the laminated marble material are aimed to be introduced which are thought to have advantages in terms of flawless connection details, easy application, transportation and storage processes in comparison to the marble material for the case of coating surfaces with similar quality. Besides many advantages, the only disadvantage of the material is said to be the supply process of the material, i.e. the necessity of importation. In this context, the evaluation of the laminated marble material in terms of being used in architecture and the types of the advantages presented by the material are all listed at the end of the research. Finally, the application of laminated marble became a successful process by gaining qualification to the marble and making the material prominent. Marbles, the earliest construction materials, come in sight for the last time after being laminated and take its place among the modern construction materials.
However, the main reason for not preferring the laminated marble material is the importation necessity for the supply of this material, since this new technology does not exist in our country yet. Therefore, our internal dynamics should develop this technology in our country as soon as possible by the help of the instinct of using our sources in a qualified manner. Unfortunately, our country cannot use its natural sources qualitatively; then the foreign investors take the control of our stone quarries. As a result of this handover process, the foreign investor exporting raw material to his own country can use his country's labor force by producing the material not-existing in his country and make more money on the final product. The exportation of raw materials from our country that can produce many technologies and products is a serious problem on which we should think earnestly. Consequently, the desired goal for our country, rich of natural sources, is to come to a point of exporting final product instead of exporting block raw material by well-managing our own sources and bringing the qualified raw material with the qualified workmanship together.

In the light of all these information, the laminated marble material should be produced in our country to make its supply process easier, and its use in application should be made widespread. However, beside the widespread use of the laminated marble, the use of natural sources should be qualitative and the natural degradation should be prevented by taking precautions during the production and consumption processes of the material.

\section{Conclusion}

In conclusion, the laminated marble material is a new material developed in many aspects in comparison to the traditional marble in Turkey. Therefore, the laminated marble having advantages compared to marble in terms of excellent joint details, easy application, eco-friendly structure, transportation and storage is also an environmentalist, innovator and technological material. The advantages of laminated marble are- Cost effective; cost saving of nearly $50 \%$ from the solid natural marble. Lower installation cost; installation can be carried out by tilers with reduced labour cost as much as amount $30-50 \%$ as compared to marble installer Easy installation and time saving High impact strength up to $45 \mathrm{MPa}$ with high attachment strength Light weight for site handling and low transportation cost. More consistent color tone and veins matching; the coverage of the laminated marble is $800 \mathrm{~m}^{2}$ compare to $200 \mathrm{~m}^{2}$ for solid marble per block. Sizes available are $300 \times 600 \mathrm{~mm}, 600 \times 600 \mathrm{~mm}, 800 \times 800 \mathrm{~mm}$ and $600 \times 1200 \mathrm{~mm}$.

\section{REFERENCES}

Altınçiçek Atilla (2001). Regional and local criteria's based on opening of the marble quarries, Turkey III. 
Marble Symposium (MERSEM'2001), Proceeding Book, 3-5 May 2001, Afyon: 235-247.

Caran Şemsettin (2014). An Overview on the marble potential of Isparta, National Marble and Stone Quarries Repair Techniques Symposium, 18-20 September 2014, Isparta: 242-254.

Casvino MarbleCer (2015), http://www.casvino.com.cn/, accessed on $5^{\text {th }}$ April 2015

Faroz Group (2015), Floor Polishing, http://www. farozgrup. com/zemin_cilalama.html, accessed on $4^{\text {th }}$ April 2015

Keleş Emine, Akten Sibel, Gül Atila and Akten Murat (2014). Determination of criteria and priorities For Selection of the Most appropriate Place of The marble and stone quarries, National Marble and Stone Quarries Repair Techniques Symposium, 18-20 September 2014, Isparta: $127-139$.

Laminated Marble (2015), Stone Inspiration SDN BHD, The Advantages of laminated marble http://www. stoneinspiration.com.mypro_laminated_marble.html (accessed on $3^{\text {rd }}$ April 2015)

Marmocer (2015). http://www.marmocer.com/EN/(accessed on $5^{\text {th }}$ April 2015)
Marmocer Turkey (2015). http://www. marmocerturkiye. $\mathrm{com} /\left(\right.$ accessed on $5^{\text {th }}$ April 2015)

Orangan Turgay, Köse Halil and Deliormanl, Hamdi (2006). Marble, chamber of mining engineers of Turkey, Kozan Publishing, Ankara, ISBN: 9789753958479.

Özçelik Hasan, Çinbilgel İlker, Koca Ahmet and Muca Belkıs (2014). Effects of marble quarries on Burdur region flora, National Marble and Stone Quarries Repair Techniques Symposium, 18-20 Eylül 2014, Isparta: 191 $-204$.

Özgül Fatih (2010). The economic importance and usability as marble of lime stones in region Sütçüler-Eğridir Aşağı Gökdere (Isparta), Master Thesis, Süleyman Demirel University, Graduate School of Applied and Natural Sciences, Isparta: 28.

Tavşan Filiz (2012). Standard, Economic and Technical Journal, 51 (606): 54-61.

Tosun Abdurrahman and Tatar Çelik (2007). Investigation on the possibilities to increase marble export of Turkey, Dokuz Eylül University Engineering Faculty, Journal of Science and Engineering, 9 (3): 13-20. 